\title{
Circulation of Respiratory Syncytial Virus in Morocco during 2014-2016: Findings from a sentinel-based virological surveillance system for influenza
}

A. Bimouhen', F. El Falaki', H. Ihazmad', Z. Regragui', S. Benkerroum ${ }^{7}$ and A. Barakat ${ }^{1}$

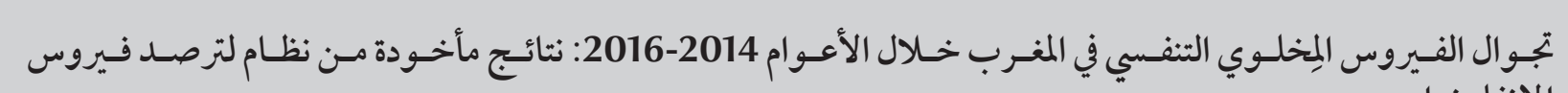

$$
\begin{aligned}
& \text { عبد الرحمان بيموحن، فاطمة الفلكي، حسن احزماض، زكية الركراكي، سميرة بنكروم، آمال بركات }
\end{aligned}
$$

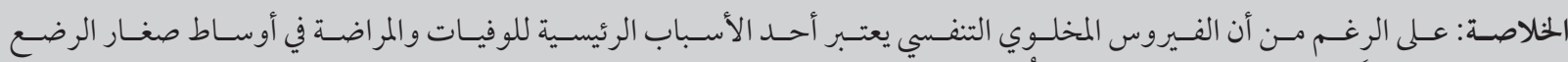

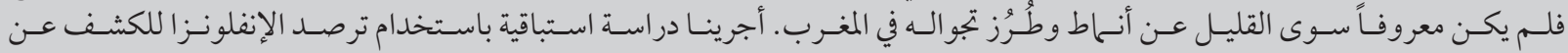

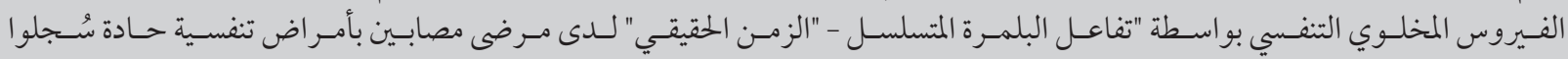

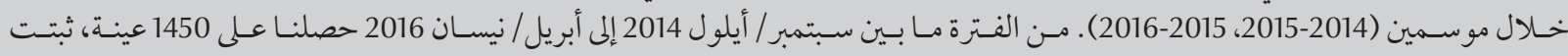

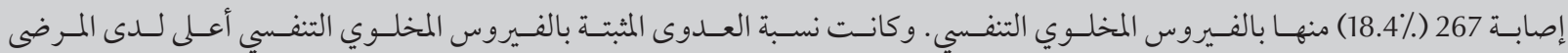

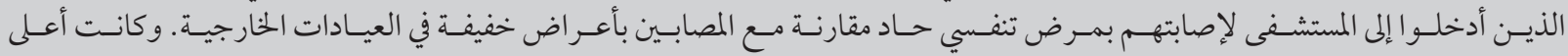

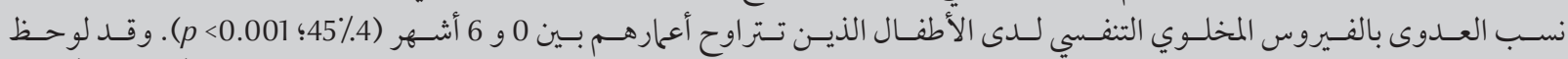

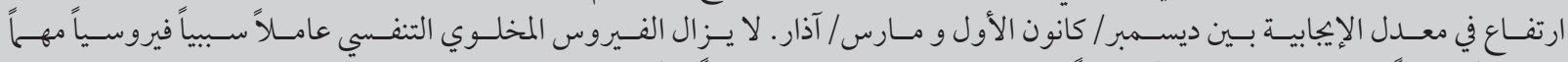

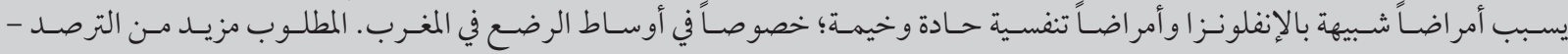

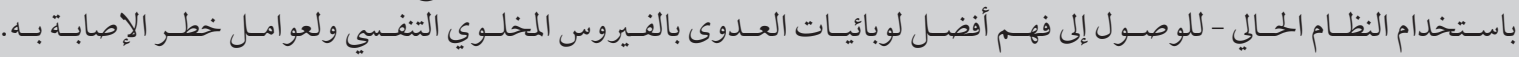

ABSTRACT Respiratory syncytial virus (RSV) is a leading cause of mortality and morbidity in young infants, little was known on its circulation types and patterns in Morocco. We conducted a prospective study using sentinel-based influenza surveillance to detect RSV by real time PCR in patients with acute respiratory infections, enrolled during two seasons (2014/15, 2015/16). During September 2014-April 2016, we obtained 1450 specimens, of which 267(18.4\%) tested positive for RSV. The proportion of positive RSV infection was higher in patients hospitalized with acute respiratory infection compared to those with mild symptoms in out-patient clinics. The proportion of RSV infection was highest in children aged 0-6 months (45\%; $\mathrm{P}<0.001)$. Higher positivity rate was observed between months of December and March. RSV remains important viral etiological agent causing influenza-like illness and severe acute respiratory infections especially among infants in Morocco. Further surveillance, is required to understand better the risk factors of RSV infections.

Circulation du virus respiratoire syncytial au Maroc de 2014 à 2016 : constatations provenant du système de surveillance virologique sentinelle de la grippe

RÉSUMÉ Bien que le virus respiratoire syncytial (VRS) soit l'une des principales causes de mortalité et de morbidité chez les jeunes nourrissons, les modes et les tendances de la circulation de ce virus au Maroc sont très peu connus. Nous avons réalisé une étude prospective en recourant à la surveillance de la grippe basée sur des sites sentinelles dans le but de dépister le VRS grâce à la PCR en temps réel chez des patients souffrant d'infections respiratoires aiguës recrutés au cours de deux saisons (2014-2015 et 2015-2016). De septembre 2014 à avril 2016, nous avons prélevé 1450 échantillons, parmi lesquels 267 (18,4\%) se sont avérés positifs au VRS. La proportion d'infections positives au VRS était plus élevée chez les patients hospitalisés pour une infection respiratoire aiguë que chez les patients en consultation externe souffrant de légers symptômes. Cette proportion était la plus élevée chez les enfants de 0 à 6 mois $(45 \% ; p<0,001)$. Le pic du taux de positivité a eu lieu de décembre à mars. Le VRS demeure un agent étiologique viral important au Maroc, responsable de syndromes de type grippal et d'infections respiratoires aiguës sévères, en particulier chez les nourrissons. Une surveillance renforcée est indispensable pour mieux comprendre les facteurs de risque des infections à VRS. 


\section{Introduction}

Respiratory syncytial virus (RSV) is a leading cause of severe respiratory disease in infants, young children and immunocompromised and elderly populations worldwide with highest burden of disease in low-income and middle-income countries. (1). The RSV infects more than $60 \%$ of children in their first year of life (almost 100\%) by age of 2 years) with peak hospital admission from RSV-related disease at 2-3 months. (2). In Morocco, 13\% of paediatric deaths during 2012 were due to acute respiratory infections (3). The burden of RSV as attributable cause of death amongst these paediatric patients remained unknown.

Although respiratory infections can be caused by bacteria and fungi, viruses remain the most frequent etiological agents (4). Respiratory syncytial virus (RSV) is recognized to be the most important viral pathogen causing acute lower respiratory tract infection in young children less than five years of age causing seasonal outbreaks worldwide $(5,6)$. While RSV is a common agent of respiratory infections causing bronchiolitis, pneumonia, and chronic obstructive pulmonary infections in people of all ages, RSV is also responsible for nosocomial infections resulting in prolonged hospital stay in intensive care units resulting in worsening the prognosis of the patients. RSV is seasonal, occurring in the winter months in temperate climates (7).

$\mathrm{RSV}$ is a non-segmented negativesense single-stranded enveloped RNA virus that belongs to the family of Paramyxoviridae, genus Pneumovirus, subfamily Pneumovirinae. There are two subgroups of the virus, $A$ and $B$, which distinguishes on both genetic and antigenic sides (8).

In Morocco, there are limited data on the circulation of RSV, its sub-types as well as the pre-dominant epidemiological and clinical characteristics of the
RSV infection. In an effort to address this gap, virological data from the existing influenza surveillance system in the country was used to understand characteristics and circulating patterns of RSV in patients with acute respiratory infections admitted in either hospitals or seen at out-patient clinics in Morocco over the period of 2014-2016.

\section{Methods}

\section{Study design and case definition}

The Ministry of Health of Morocco established a sentinel-based influenza surveillance system in 1996 (9). The surveillance system for influenza and influenza-like illness (ILI) was revamped in 2014 that currently includes- (i) surveillance system for severe acute respiratory infection (SARI) using the WHO's case definition for SARI (10). The system collects data from 8 public sectorgeneral hospitals located in all the eight regions in the country; (ii) surveillance system for influenza-like illness (ILI) using the WHO's case definition for ILI (10). The system collects data from out-patients over 425 out-patient clinics in both public and private sector.

While the SARI surveillance is conducted throughout the year for hospitalized patients. Both epidemiological and virological data are collected from all SARI cases that meet the WHO's case definition for SARI. The patients admitted in either paediatrics, pneumology or internal medicine are enrolled for the SARI surveillance system.

The surveillance system for ILI is conducted in 375 public sector outpatient clinics and aggregated data (number of ILI cases out of total consultations, etc) on total ILI and ARI consultations are collected from all these 375 public sector clinics. Of these, 8 out-patient clinics collect specimen for virological testing only. The first five cases meeting the WHO's case definition for ILI are enrolled for specimen collection.

In addition to the public sector clinics, the ILI surveillance system in Morocco also uses a private practitioner network comprising of 50 physicians (including general practitioners, pediatricians and lung specialists) located in 9 large cities across the country (Tanger, Fès, Meknès, Oujda, Casablanca, Rabat, Marrakech, Agadir and Laayoune). The physicians enroll the first 5 ILI cases per day during October through April for specimen collection

For the purpose of understanding the circulation and characteristic of circulating RSVs, the National Influenza Center (NIC), based in Rabat, Morocco, collected and tested the patient's specimens from its existing influenza surveillance system for RSVs over a period from September 2014 to April 2016. Additional epidemiological data using a standardized data collection instrument were also collected from 8 SARI and 33 ILI sites. Patient's specimens from a total of 1450 patients meeting the case definition for either ILI and SARI were collected.

\section{Sample and data collection}

Both nasopharyngeal (NP) and oropharyngeal (OP) swabs were collected from 1450 patients who met the case definition for either ILI or SARI. The specimens were placed in tube containing $3 \mathrm{~mL}$ of viral transportation medium $(\mathrm{ViCUM})$, stored at $4^{\circ} \mathrm{C}$ at the health facilities, and sent to the NIC within 48hours. A standardized questionnaire with patient-specific information (medical history, clinical symptoms, demographic and epidemiological data) was filled up by trained personnel.

\section{Nucleic acid extraction}

Total nucleic acids were extracted automatically from $400 \mu \mathrm{L}$ of samples, using a High Pure Viral Nucleic Acid Kit and iPrep" instrument, according to the manufacturer's instructions 
(Lifetechnologies, Carlsbad, USA), thereafter (RNAse $\mathrm{P}$ ) was considered as the internal control during extraction of human specimens. $100 \mu \mathrm{L}$ of extracted nucleic acids were stored at $-70^{\circ} \mathrm{C}$ until processing.

\section{Detection of RSV\& Influenza by real time RT-PCR}

All enrolled patients were tested for both influenza and RSV viruses. Detection of these two viruses was performed in $5 \mu \mathrm{L}$ volume using Invitrogen Superscript III Platinum One-step RT-PCR, amplification and reaction conditions were in accordance to the protocols developed by Centers for Disease Control and Prevention (CDC; Atlanta, GA) (11,12), with an ABI 7500 Fast Sequence Detection System.

\section{Subtyping of RSV by real time RT-PCR}

The real-time RT-PCR for Subtyping RSV was performed with primers specific to the N gene of RSVA and RSVB, the amplification protocol was $50^{\circ} \mathrm{C}$ for $30 \mathrm{~min}$, followed by $95^{\circ} \mathrm{C}$ for $2 \mathrm{~min}$, and then by and 45 cycles of $15 \mathrm{~s}$ at $94^{\circ} \mathrm{C}$, and $35 \mathrm{~s}$ at $55^{\circ} \mathrm{C}(13,14)$.

\section{Statistical analysis}

To describe the temporal distribution of RSV positive cases, we aggregated RSV results as obtained by RT-PCR by calendar month and week. Demographic, clinical and virological data for all enrolled patients were entered into a database created using Epi Info 7.1. Group comparisons were performed using $\chi 2$ or Fisher's exact test for the dependency/relationship between two variables. P-values $<0.05$ were considered statistically significant. Data analysis was conducted using the same software.

\section{Ethical considerations}

The protocol was approved by the Ministry of Health for the objective of conducting surveillance of respiratory diseases with epidemic potential, in which participants remain anonymous, and therefore did not require an assessment of the ethics committee or IRB approval. Verbal consent was obtained from all patients.

\section{Results}

\section{Demographic characteristics}

During the period of 2014-2016, patient's specimens were collected from 1450 patients meeting the WHO's case definition for ILI and SARI from all age groups from 41 sentinel sites for SARI and ILI. An NP/OP swab was collected from all those patients. Of those, 842 (58\%) patients specimens were collected from the ILI sites while the remaining 608 (42\%) patients specimens were enrolled from the SARI sentinel sites. The proportion of females was slightly greater than the proportion of males whose specimens were collected during the period of 20142016. ( $52.2 \%$ vs. $47.8 \%$ ). The mean age in years of patients was 24.41 years $( \pm 23.69)$ and the median age was 18.00 years [0.08-89.00]. A total of 503 cases (35\%) were younger than 5 years, 608 cases (42\%) were aged between 5-49 years while 283 patients (20\%) were older than 50 years (Table 1). Among the eight regions, highest number of patients specimens were collected from Fes-Meknes (549/38\%) followed by Rabat-Sale -Kenitra (405/28\%). Patients were enrolled for this study throughout the year but during the first quarter (January-April), the number of enrollment was higher compared to other quarters.

\section{Detection rates of RSV, percentages of positives and subgroups}

Of the 1450 specimens tested from both ILI and SARI, a total of 267 specimens were positive for RSV by RT-PCR resulting in the detection rate of $18.4 \%(267 / 1450)$. The detection rate for RSV, plausibly, was comparably higher amongst the patients presenting with SARI than ILI ( $73 \%$ vs. $27 \%$ ). The proportion of RSV infection detection was highest in children $(P$ $<0.001$ ), aged between $0-6$ months $(45 \% ; 121 / 267)$ followed by those aged between 7-23 months old (19\%; $52 / 267)$, children aged between $2-4$ years $(12 \% ;(31 / 267)$ and adults between $15-49$ years $(9 \% ; 25 / 267)$.

We were able to determine the subtypes of RSV in all 267 samples that were positive for RSV. During 2014/15 season, $92 \%$ (80 of 87 ) of RSV strains were sub-typed as RSV A which was the predominant strain compared to only $8 \%$ (7 of 87 ) of RSV strains sub-typed as RSV-B.On the other hand, RSV B was the predominantly circulating during 2015/16 season accounting for $70.5 \%$ of all RSVstrains circulating in the country during this period (127 patients with RSV Group B among 180 RSV positive samples in 2015/16) (Figure 1).

\section{RSV seasonal distribution and co-circulation with influenza viruses}

Throughout the period under observation, the RSV showed a periodic circulating pattern. Positivity rate is predominately observed to have occurred from November to March of the year (during the fourth and the first quarters of year each season; $P<0.001$ ); peaks were detected during week 52 of 2014 and week 03 of 2016 (Figure 2).

The largest proportion of samples (89\%) were collected from patients in main five regions of the country-: Fes-Meknes, Rabat-Sale-Kenitra, Souss-Massa, Beni mellal-Khenifra and Oriental. Most of RSV-positive samples (97\%; P < 0.001$)$ were collected from these 5 regions. During the period of 2014-2016, both the RSV and Influenza viruses (Table 2) were also observed to be co-circulating $(18 \% ; 267 / 1450$ versus $31 \%$; $447 / 1450$ ) 


\begin{tabular}{|c|c|c|c|c|}
\hline & $\begin{array}{l}\text { No of patients } \\
\text { enrolled }\end{array}$ & RSV-Positive & RSV-Negative & $P$-value \\
\hline & $N=1450$ & $\mathrm{~N}=267(18 \%)$ & $\mathrm{N}=1183(82 \%)$ & \\
\hline & $n(\%)$ & $n(\%)$ & $n(\%)$ & \\
\hline \multicolumn{5}{|l|}{ Age $(n=1395)$} \\
\hline 0-6 month & $217(15)$ & $121(45)$ & $96(8)$ & \multirow{8}{*}{$<0.001$} \\
\hline $7-23$ month & $153(11)$ & $52(19)$ & $101(9)$ & \\
\hline 2-4 year & $134(9)$ & $31(12)$ & $103(9)$ & \\
\hline 5-14 year & $150(10)$ & $7(3)$ & $143(12)$ & \\
\hline 15-49 year & $458(32)$ & $25(9)$ & $433(37)$ & \\
\hline 50-64 year & $200(14)$ & $16(6)$ & $184(16)$ & \\
\hline$>65$ year & $83(6)$ & $7(3)$ & $76(6)$ & \\
\hline unknown & $55(4)$ & $8(3)$ & $47(4)$ & \\
\hline \multicolumn{5}{|l|}{ Sex } \\
\hline Female & 757 (52) & $129(17))$ & $628(83)$ & \multirow[t]{2}{*}{0.159} \\
\hline Male & $693(48)$ & $138(20)$ & $555(80)$ & \\
\hline \multicolumn{5}{|l|}{ Clinical symptoms } \\
\hline \multicolumn{5}{|l|}{ onset of symptoms } \\
\hline$>10$ days & & 35 (15) & $198(85)$ & \multirow[t]{2}{*}{0.145} \\
\hline$<10$ days & & 232 (19) & $985(81)$ & \\
\hline Fever $(n=752)$ & & & & 0.458 \\
\hline$\leq 37.5 \mathrm{C}$ & & $3(12)$ & $22(88)$ & \\
\hline$>37.5 \mathrm{C}$ & & 129 (18) & $598(82)$ & \\
\hline \multicolumn{5}{|l|}{ Cough } \\
\hline Yes & & $246(20)$ & $975(80)$ & \multirow{2}{*}{$<0.001$} \\
\hline No & & $21(9)$ & $208(91)$ & \\
\hline \multicolumn{5}{|l|}{ The regions $(n=1450)$} \\
\hline Fes-Meknes & $549(38)$ & $133(50)$ & $416(35)$ & \multirow{8}{*}{$<0.001$} \\
\hline Rabat-Sale-Kenitra & $405(28)$ & 49 (18) & $356(30)$ & \\
\hline Souss-Massa (Agadir) & $159(11)$ & $41(15)$ & $118(10)$ & \\
\hline Beni mellal-Khenifra & $98(7)$ & $27(10)$ & $71(6)$ & \\
\hline Oriental (Oujda) & $88(6)$ & $9(3)$ & $79(7)$ & \\
\hline Tanger-Tetouan & $92(6)$ & $4(2)$ & $88(7)$ & \\
\hline Marrakech-Safi & $52(4)$ & $4(2)$ & $48(4)$ & \\
\hline Laayoune-Dakhla & $7(0)$ & $0(0)$ & $7(0)$ & \\
\hline \multicolumn{5}{|l|}{ Season } \\
\hline First Quarter & $1033(71)$ & $230(86)$ & $803(68)$ & \multirow{4}{*}{$<0.001$} \\
\hline Second quarter & $41(3)$ & $1(0)$ & $40(3)$ & \\
\hline Third quarter & $11(1)$ & $0(0)$ & $11(1)$ & \\
\hline Fourth quarter & $365(25)$ & $36(13)$ & $329(28)$ & \\
\hline \multicolumn{5}{|l|}{ Syndrome } \\
\hline ILI & $842(58)$ & $73(27)$ & 769 (65) & \multirow{2}{*}{$<0.001$} \\
\hline SARI & $608(42)$ & $194(73)$ & $414(35)$ & \\
\hline
\end{tabular}

*Some data variables from age, clinical syndrome and regions have not been included in the analysis owing to incomplete data.

\section{Clinical manifestations}

For all age groups, the commonest presenting symptoms of RSV-positive cases were cough $(92.1 \% ; P<0.001)$. within 10 days of admission while it The onset of symptoms for RSV- was $81 \%$ for RSV-negative patients positive patients was in $19 \%$ of patients $\quad(81 \% ; P=0.145)$. Fever $(>37.5 \mathrm{C})$ was 


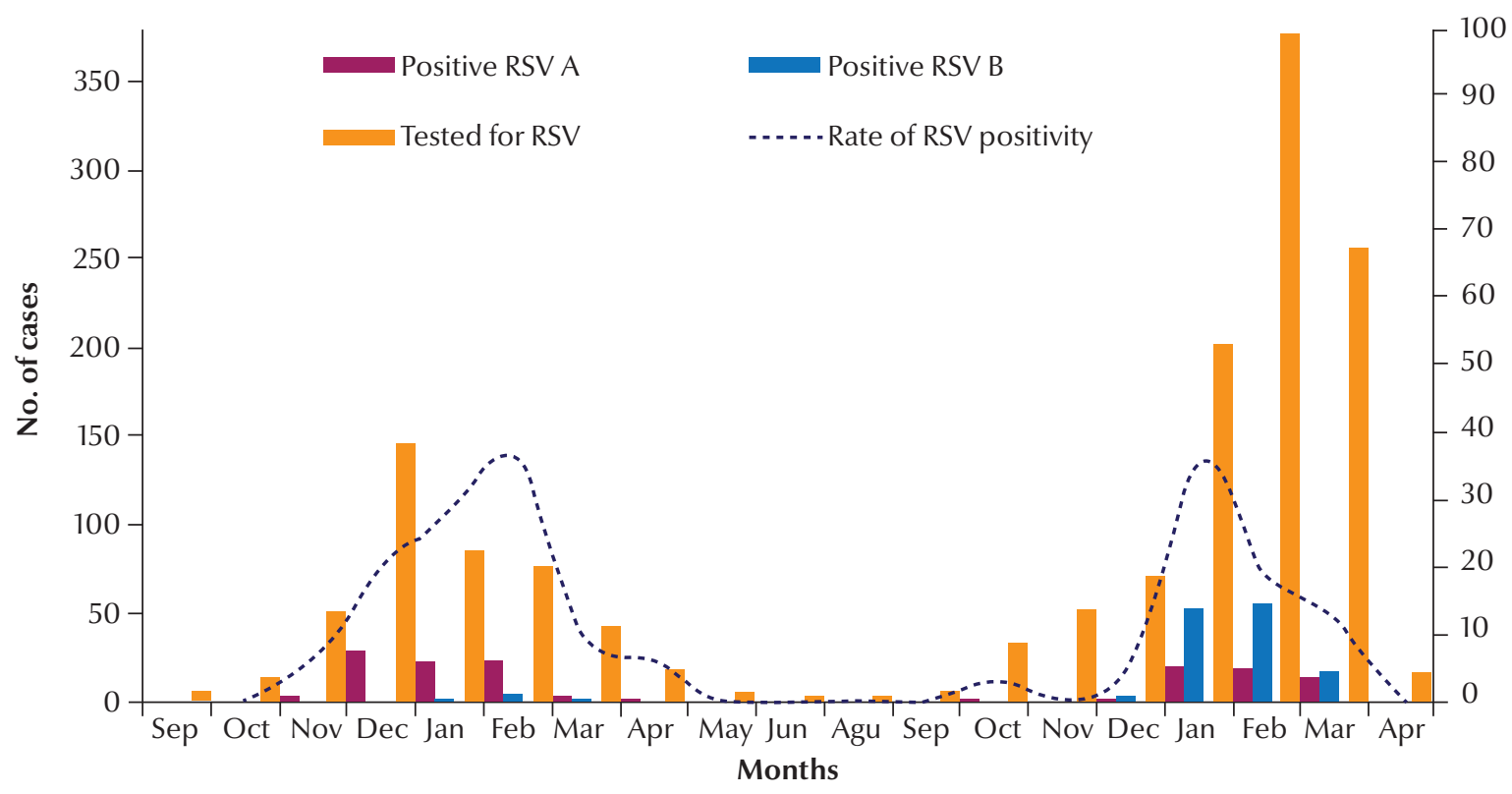

Figure 1 Samples tested for RSV, proportion positive for RSV A and RSVB, and positivity rates by months, Morocco, September 2014-April 2016.

found in only 18\% (129/752) of RSVpositive patients compared with RSVnegative patients ( $(82.0 \% ; P=0.458)$. Further, in infants aged between $0-6$ months affected by RSV, only $60.3 \%$ (73/121) presented with fever during the period the data were collected.

\section{Discussion}

Using data from sentinel-based surveillance system for influenza, we report for the first time ever the circulating patterns of RSV in Morocco during 2014-2016. We have detected RSV by singleplex Real-Time RT-PCR in patients with severe acute respiratory infections who were enrolled in the sentinel-based influenza surveillance network in Morocco during the period of 2014-2016. Among the patients whose specimens were collected during 2014-2016 from the SARI and ILI sentinel sites, the rate of RSV positivity was $18.4 \%$.

Although, RSV was detected in all age groups, the proportion of positive cases for RSV was comparatively higher in children aged between 0-6 months amongst all age groups which was statistically significant. Children below 5 years of age comprised of $35 \%$ of all patients enrolled in this study while the RSV detection rate in children under 5 years of age was $76 \%$. This rate was high compared to the findings reported in USA and Turkey with 18\% and $24.5 \%$ respectively (6-15).Similar to our findings, Weber et al. reported higher percentage of RSV-infection in children less than 6 months of age in developing countries (16). In this study, the higher percentage of RSV infection among infants may probably be due to nosocomial spread of the virus within paediatric care units during the high circulating season of RSV. However, there is no data to substantiate this assumption. Indeed, some authors suggested RSV as the major cause of nosocomial outbreak during its annual outbreaks, specially among the children admitted in the paediatric unit (17).

Consistent with other studies ( 1 , 4-6), we also found that proportion of patients with respiratory illness who tested positive for RSV varied with age, with the highest overall detection rate occurring in infants less than 6 months of age during 2014-2016 (45\%; P < $0.001)$ making this age category the highest priority target population for the candidate vaccines $(1,18)$.

The circulation of RSV follows a clear seasonality pattern. In temperate climate, RSV usually circulates during the winter season from November to April. Epidemics of RSV occurs when the circulation of influenza virus peak in the period from October through April (9). Although no clear seasonal pattern on the circulation of RSVs could be gathered from these data, the detection rate for RSV-positive infection was highest from November to March every year (during the fourth and the first quarter; $P<0.001)$ while the detection rate was observed to have peaked in our study during week 52 of 2014 and week 3 of 2016. Similar circulating pattern has been observed in other temperate countries, where RSV-positive infection rate begins in late fall or early winter, peaks between mid-December and early February, and offset in late spring $(7,8,16)$. Alternating strong early onset epidemics with more moderate and 


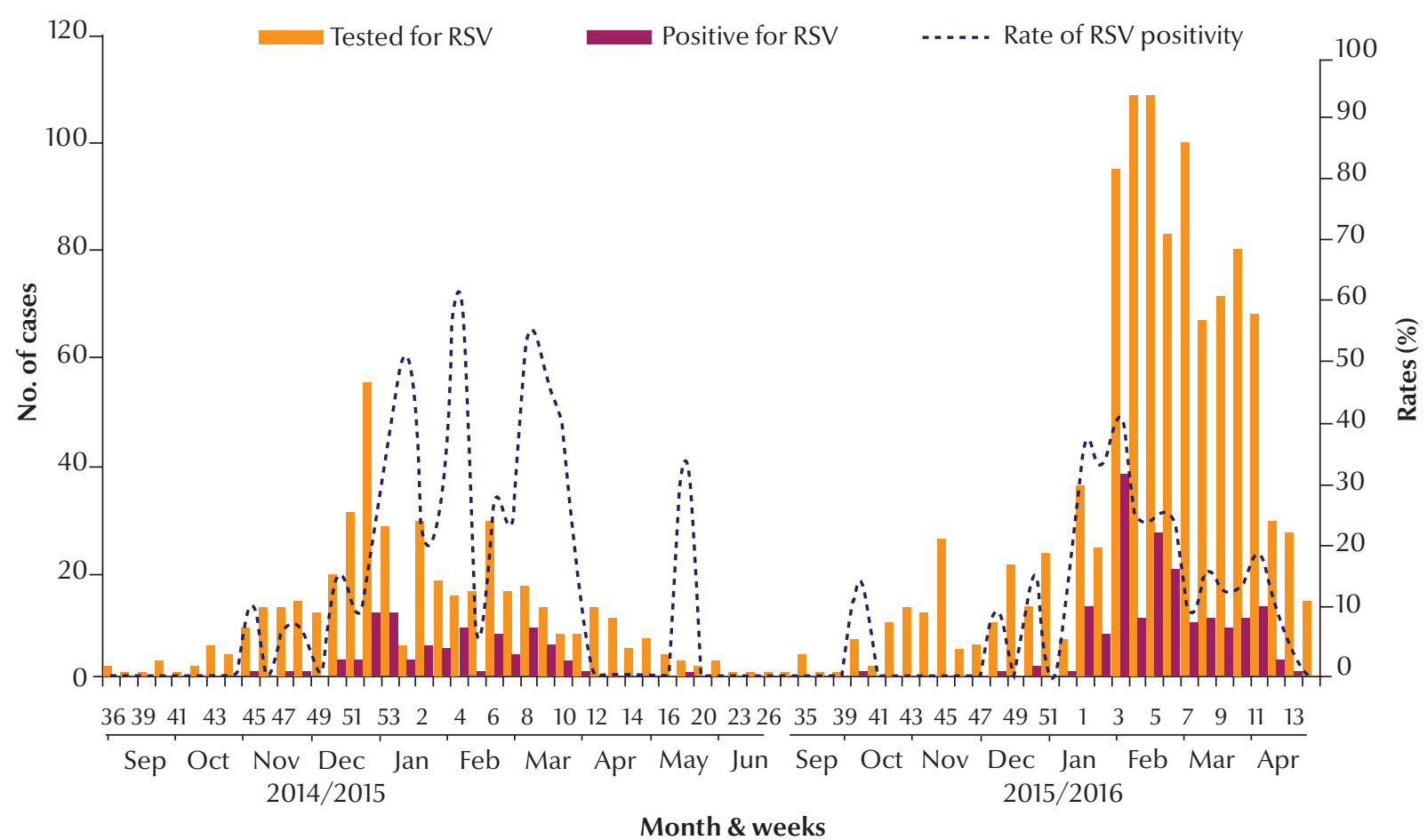

Figure 2: Samples tested for RSV and proportion positive for RSV by weeks and -months, Morocco, September 2014-April 2016

later epidemics have also been reported in the temperate region (19).

The data reveal that that RSV positivity was highest among patients enrolled from five regions (Fes-Meknes, Rabat -Sale -Kenitra, Souss-Massa, Oriental and Beni mellal-Khenifra) reaching to a combined rate of approximately $97 \%$. This could be due to fact that these regions are most populated in Morocco and therefore, comparatively higher numbers of patients were enrolled (89\%) from these regions than the other remaining regions in the SARI and ILI surveillance system.

In addition to the higher percentage of RSV infection in infants aged
0-6 months, we also observed in our study that $40 \%$ of these infants infected with RSV did not have fever as the predominant presenting symptom during 2014-2016. Indeed, WHO reported that nearly half of RSV-infected children do not show fever as the presenting symptom (20). Another report found that the burden of RSV would have been under-estimated by $50-85 \%$ among young children if only SARI and ILI case definitions are used to pick up a probable RSV infected children. This underlines the importance of using WHO's case definition for ARI as more suitable and highly sensitive for RSV surveillance amongst children (21).

\begin{tabular}{|c|c|c|c|}
\hline \multicolumn{4}{|c|}{$\begin{array}{l}\text { Table } 2 \text { Influenza and RSV positivity rate among ILI and SARI patients, Morocco, } \\
\text { 2014-2016. }\end{array}$} \\
\hline \multirow[t]{2}{*}{ Pathogen } & \multicolumn{2}{|c|}{ RT-PCR Test Results } & \multirow[t]{2}{*}{ Total } \\
\hline & Negative & Positive & \\
\hline$R S V$ & 1,183 (82\%) & $267(18 \%)$ & $1,450(100 \%)$ \\
\hline Influenza virus & $1,003(69 \%)$ & $447(31 \%)$ & $1,450(100 \%)$ \\
\hline
\end{tabular}

In our data, both subtypes of RSV were detected during each season. While higher number of RSV group A viruses (92\%) were detected amongst patients who were tested positive for RSV during 2014/15, the pattern was changed during the following season of $2015 / 16$. During this period, there was a decline in the circulation of RSV group A viruses and RSV group B viruses predominantly circulated during this season accounting for $70.5 \%$ of all RSVinfected cases. Esposito et al. reports that RSV has complex circulation patterns characterized by periodic replacement of the predominant genotypes with new one during successive epidemic seasons (22). Additional investigations are needed to determine the genotypes of RSV strains circulating in Morrocco, since many reports described the novel RSVA genotype ON1 in the world as well as the increasing spread of the RSV group B virus genotype BA.

There are several limitations to the way these data presented in this 
manuscript need to be interpreted. First, our sample size was small. We did not collect swab specimens from all patients meeting the case definition for ILI and the possibilities that some SARI patients that were eligible for enrolment were not included for patient's specimen collection owing to either incorrect use of case definition or selection bias cannot be ruled out. Hence there are possibilities for sampling bias in some cases. Second, data on the full epidemiological spectrum of patients positive for RSV infection including the risk factors were not collected. Third, owing to small sample size, the association between RSV subtypes and other clinical and epidemiological characteristics and severity of infection could not be established. Fourth, to establish seasonality of the RSV's circulating patterns, more time-series analysis of data are required over 3 to 5 year period. Finally, the molecular characterization of the RSV group viruses could not be done during this study.

\section{Conclusion}

This study underscored the importance of RSV as a viral aetiological agent causing both mild and severe acute respiratory infections in Morocco, especially in children aged less than 5 years. Additional sentinel based surveillance embedded in influenza surveillance will be required to be established in order to fully understand the burden of disease caused by RSVs including epidemiology, seasonality and risk factors for the RSV infection in Morocco. Further research will also be required using molecular epidemiology for characterization of predominantly prevalent RSV strains in different regions of Morocco and its prevalent age groups for early detection of emerging genotypes responsible for causing periodic outbreaks.

\section{Acknowledgments}

We would like to acknowledge all the physicians and nurses in the public and private network who have contributed to the collection of samples at the sentinel sites.

Funding: This work was supported through funding by the Centers for Disease Control and Prevention (CDC) grant no. 5U51CI000469 and PIP.

Conflicting interests: None declared.

\section{References}

1. Collins PL, Melero JA. Progress in understanding and controlling respiratory syncytial virus: still crazy after all these years. Virus Res. 2011 Dec;162(1-2):80-99. PMID:21963675

2. WHO. The World Health Report 2003: Shaping the Future. Geneva, Switzerland: World Health Organization; 2003.

3. Imane Jroundi, Chafiq Mahraoui, Rachid Benmessaoud, Cinta Moraleda, Badr Sououd Benjelloun and Quique Bassat. Knowledge gaps on paediatric respiratory infections in Morocco, Northern Africa. Archives of Public Health 12/2015; 73(1). DOI: 10.1186/s13690-015-0076-x.

4. Costa LF, Yokosawa J, Mantese OC, Oliveira TF, Silveira HL, Nepomuceno LL, et al. Respiratory viruses in children younger than five years old with acute respiratory disease from 2001 to 2004 in Uberlândia, MG, Brazil. Mem Inst Oswaldo Cruz. 2006 May;101(3):301-6. PMID:16862327

5. Nair H, Nokes DJ, Gessner BD, Dherani M, Madhi SA, Singleton RJ, et al. Global burden of acute lower respiratory infections due to respiratory syncytial virus in young children: a systematic review and meta-analysis. Lancet. 2010 May 1;375(9725):1545-55. PMID:20399493

6. Hall CB, Weinberg GA, Iwane MK, Blumkin AK, Edwards KM, Staat MA, et al. The burden of respiratory syncytial virus infection in young children. N Engl J Med. 2009 Feb 5;360(6):58898. PMID:19196675

7. Aitken C, Jeffries DJ. Nosocomial spread of viral disease. Clin Microbiol Rev. 2001 Jul;14(3):528-46. PMID:11432812

8. Borchers AT, Chang C, Gershwin ME, Gershwin LJ. Respiratory syncytial virus-a comprehensive review. Clin Rev Allergy Immunol. 2013 Dec;45(3):331-79. PMID:23575961

9. Barakat A, Ihazmad H, Benkaroum S, Cherkaoui I, Benmamoun A, Youbi $M$, et al. Influenza surveillance among outpatients and inpatients in Morocco, 1996-2009. PLoS One. 2011;6(9):e24579. PMID:21931764
10. World Health Organization (WHO). WHO surveillance case definitions for ILI and SARI. Geneva: WHO. January 2014. [Accessed 11 Jul 2016.] Available from: <http://www.who. int/influenza/surveillance_monitoring/ili_sari_surveillance_ case_definition/en/>

11. Centers for Disease Control and Prevention. Real-time RTPCR assays for non-influenza respiratory viruses. Version 1.4 (unpublished), Atlanta: CDC, 2009.

12. WHO. CDC protocol of real time RT-PCR for detection and characterization influenza 2009 A (H1N1) pdm virus. 2009.

13. Hu A, Colella M, Tam JS, Rappaport R, Cheng SM. Simultaneous detection, subgrouping, and quantitation of respiratory syncytial virus A and B by real-time PCR. J Clin Microbiol. 2003 Jan;41(1):149-54. PMID:12517840

14. de-Paris F, Beck C, Machado AB, Paiva RM, da Silva Menezes $D$, de Souza Nunes L, et al. Optimization of one-step duplex real-time RT-PCR for detection of influenza and respiratory syncytial virus in nasopharyngeal aspirates. J Virol Methods. 2012 Dec;186(1-2):189-92. PMID:22796284

15. Çiçek C, Arslan A, Karakuş HS, Yalaz M, Saz EU, Pullukçu H, et al. [Prevalence and seasonal distribution of respiratory viruses in patients with acute respiratory tract infections, 2002-2014]. Mikrobiyol Bul. 2015 Apr;49(2):188-200. PMID:26167819

16. Weber MW, Mulholland EK, Greenwood BM. Respiratory syncytial virus infection in tropical and developing countries. Trop Med Int Health. 1998 Apr;3(4):268-80. PMID:9623927

17. Mlinaric-Galinovic G, Varda-Brkic D. Nosocomial respiratory syncytial virus infections in children's wards. Diagn Microbiol Infect Dis. 2000 Aug;37(4):237-46. PMID:10974574

18. Anderson LJ, Dormitzer PR, Nokes DJ, Rappuoli R, Roca A, Graham BS. Strategic priorities for respiratory syncytial virus (RSV) vaccine development. Vaccine. 2013 Apr 18;31 Suppl 2:B209-15. PMID:23598484 
19. Freymuth F, Vabret A, Dina J, Cuvillon-Nimal D, Lubin C, Vaudecrane A, et al. Les virus des bronchiolites aiguës. Arch Pediatr. 2010 Aug;17(8):1192-201. PMID:20558050

20. Global Influenza Programme WHO. Informal Consultation on Surveillance of RSV on the Global Influenza Surveillance and Response System (GISRS) Platform.Geneva. World Health Organisation, 2015(WHO/HSE/PED/GIP/RSV/2015.01).

21. Saha S, Pandey BG, Choudekar A, Krishnan A, Gerber SI, Rai SK, et al. Evaluation of case definitions for estimation of respira- tory syncytial virus associated hospitalizations among children in a rural community of northern India. J Glob Health. 2015 Dec;5(2):010419. PMID:26649172

22. Esposito S, Piralla A, Zampiero A, Bianchini S, Di Pietro G, Scala A, et al. Characteristics and Their Clinical Relevance of Respiratory Syncytial Virus Types and Genotypes Circulating in Northern Italy in Five Consecutive Winter Seasons. PLoS One. 201506 05;10(6):e0129369. PMID:26047100 